\title{
Peripheral Analgesic and Anti-Inflammatory Effects of Smilax canariensis in an Animal Model
}

\author{
Sandra Dévora, Susana Abdala*, Domingo Martín-Herrera \\ Unidad de Farmacología y Farmacognosia, Sección de Farmacia, Universidad de La Laguna, San Cristóbal de La \\ Laguna, Spain \\ Email: sabdala@ull.es
}

Received 4 July 2015; accepted 21 August 2015; published 24 August 2015

Copyright (C) 2015 by authors and Scientific Research Publishing Inc.

This work is licensed under the Creative Commons Attribution International License (CC BY). http://creativecommons.org/licenses/by/4.0/

c) (7) Open Access

\begin{abstract}
Smilax canariensis Brouss. ex Willd. is an endemic plant of the Canary Islands. Its rhizomes, leaves and stems have been traditionally used in Canary folk medicine to treat a wide variety of conditions including pain. Our objective is to investigate the analgesic and anti-inflammatory activities of different extracts of $S$. canariensis in Swiss mice, using established biological models for pain and inflammation, such as phenylquinone writhing test, formalin test, tail-flick test and mouse paw edema induced by carrageenan. Oral administration of $S$. canariensis extracts significantly reduce writhing episodes evoked by phenylquinone injection in a dose-dependent manner; and higher doses result in a reduction of pain similar to or higher than that of the reference drug piroxicam (59.56\%; $p<0.01$ ). The extracts also cause a marked dose-dependent inhibition of formalin-induced pain in the second phase but only minimal inhibition of tail-flick behavior, suggesting that $S$. canariensis is not a centrally acting analgesic. Finally, in the carrageenan-induced hind paw edema model, the extracts show a moderate anti-inflammatory effect, the most active being the ethyl acetate fraction at $200 \mathrm{mg} / \mathrm{kg}$ p.o. $(33.33 \% ; \mathrm{p}<0.05)$. Our results suggest that $S$. canariensis extracts have clear dose-dependent peripheral analgesic effects, which lends support to the traditional use of this medicinal plant to treat pain associated with inflammatory or other processes.
\end{abstract}

\section{Keywords}

Smilax canariensis, Smilacaceae, Medicinal Plant, Folk Medicine, Analgesic Activity, Anti-Inflammatory Activity

\footnotetext{
${ }^{*}$ Corresponding author.

How to cite this paper: Dévora, S., Abdala, S. and Martín-Herrera, D. (2015) Peripheral Analgesic and Anti-Inflammatory Effects of Smilax canariensis in an Animal Model. Pharmacology \& Pharmacy, 6, 391-400. 


\section{Introduction}

Pain constitutes a major public health problem and the primary reason why people seek medical care, and it limits productivity and diminishes the quality of life [1].

There are several therapeutic protocols for the management of pain, the most widely prescribed being non-steroidal anti-inflammatory drugs (NSAIDs), such as aspirin and ibuprofen, which reduce prostanoid formation by cyclooxygenase (COX) inhibition, and opioids, such as morphine. However, these drugs have significant side effects that limit their use, and the use of NSAIDs is associated with gastrointestinal irritation and renal function abnormalities [2], whereas opioid analgesics are limited by drug-induced tolerance, dependence and constipation. There is therefore a need for better analgesic and anti-inflammatory drugs without adverse side effects for the management of pain.

In this search, a large amount of experimental data has clearly demonstrated that plants of the genus Smilax have interesting anti-inflammatory and analgesic properties, among others [3]-[5] and seem to contain phenolic compounds and steroidal saponins as the main active principles [6]-[9].

Smilax canariensis Brouss. ex Willd. (Smilacaceae) is an endemic species of the Canary Islands, popularly known as "Zarzaparrilla sin espinas". Its rhizomes, leaves and stems are habitually employed as an oral hot water infusion in Canary Islands folk medicine due to the wide variety of medicinal properties attributed to it, including diuretic and anti-spasmodic effects, among others [10] [11].

Previous investigations on this species performed by our group have shown an interesting diuretic activity in laboratory assays, and chromatographic study by preparative thin-layer chromatography (TLC), and ${ }^{1} \mathrm{H}$ NMR spectroscopy has revealed the presence of two types of components, phenolic polar compounds and organic fatty acids [12] [13].

Taking into account the traditional analgesic use of S. canariensis and the fact that the phenolic compounds have demonstrated interesting analgesic and anti-inflammatory properties [14]-[18], we perform this research. The present study represents the first investigation into these activities of an aqueous, methanol extract and methanol extract fractions of this plant, employing laboratory mice as test animals.

\section{Materials and Methods}

\subsection{Plant Material}

Rhizomes, leaves and stems (20:40:40) of S. canariensis (Smilacaceae) were harvested in a place called Las Nieves on the island of La Palma, Canary Islands, and labeled Exp. NE. UTM E228098-N3177053. The species was identified by Dr. Pedro Pérez de Paz, Department of Plant Biology, University of La Laguna (Tenerife, Spain), where voucher specimens have been deposited (TFC 44393).

\subsection{Extract Preparation}

Rhizomes, leaves and stems of $S$. canariensis were dried in an oven at $40^{\circ} \mathrm{C}$ for four days and then cut and ground to powder by mechanical milling. Then an aqueous extract at $5 \%$ from the dried powdered plant material was prepared by simulating the traditional method applied in Canaries. Amounts of $5 \mathrm{~g}$ of pulverized plant material were placed in $100 \mathrm{ml}$ distilled boiling water and left at room temperature for 15 mins to infuse. Then it was filtered and lyophilized to obtain a powder with $15.2 \%$ yield.

In a second test procedure, the dried powdered plant material was submitted to a continuous extraction in a Soxhlet extractor (Sigma Aldrich, Germany) for 5 days using 100\% methanol (Sigma, Spain) as a solvent. The solvent was then eliminated by vacuum distillation in a rotary vacuum evaporator (Buchler Corp.), with a yield of $15.29 \%$ of the dry material extracted.

The methanol residue was partitioned between water and organic solvents of increasing polarities, to yield four new fractions, including: n-hexane, dichloromethane, ethyl acetate and n-butanol. The yields obtained for each sub-extract with respect to the dry material were: $14.35 \%, 2.97 \%, 4.71 \%$ and $24.71 \%$ respectively.

For pharmacological studies, $1 \mathrm{ml} / 40 \mathrm{~g}$ body weight (bw) of the lyophilized aqueous extract at doses of 190 , 380,570 or $760 \mathrm{mg} / \mathrm{kg}$, the methanol extract at $100,200 \mathrm{or} 300 \mathrm{mg} / \mathrm{kg} \mathrm{bw}$, and the fractions at 100 and 200 $\mathrm{mg} / \mathrm{kg}$ bw, suspended in 3\% tween 80 (Ferosa, Spain) just before administration, was then given orally to laboratory mice. The test doses and fractions were based on those used in studies performed with this species in 2008 and 2012 by Abdala et al. [12] [13]. 


\subsection{Animals}

Experiments were performed using male and female Swiss mice (20 - $30 \mathrm{~g}$ ) obtained from the Central Animal Laboratory of La Laguna University. Animals were housed at $23^{\circ} \mathrm{C} \pm 1^{\circ} \mathrm{C}$ under a $12 / 12 \mathrm{~h}$ light/dark cycle and with access to standard commercial diet and water ad libitum. On the day of experiment, after overnight fasting with water ad libitum, were acclimatized to the laboratory for at least 2 hours before performing any test and were used only once throughout the study. All procedures described here were performed according to the Directive 2010/63/EU of the European Parliament and of the Council of 22 September 2010 on the protection of animals used for scientific purposes [19], after approval by the Ethics Committee for Animal Research, La Laguna University (CEIBA 2011-0014).

\subsection{Analgesic Activity}

\subsubsection{Siegmund's Test}

Mice were divided into groups of six animals each in laboratory cages. Forty-five minutes after receiving oral administration of the aqueous extract at 190, 380 and $570 \mathrm{mg} / \mathrm{kg}$, methanol extract at $100 \mathrm{and} 200 \mathrm{mg} / \mathrm{kg}$, methanol extract fractions at 100 and $200 \mathrm{mg} / \mathrm{kg}$, piroxicam (Sigma, Spain) at $75 \mathrm{mg} / \mathrm{kg}$ (positive control) or 3\% tween 80 (negative control) respectively, each mouse was intraperitoneally injected with a solution of phenylquinone at $4 \mathrm{mg} / \mathrm{kg}$ body weight (Sigma, Spain). Immediately after the algic compound injection, each animal was placed in a transparent observation cage and we counted the number of writhing episodes during 20 mins. Writhing activity consists of a contraction of the abdominal muscles together with a stretching of the hind limbs [20].

\subsubsection{Formalin Test}

The procedure was essentially similar to that described previously by Hunskaar and Hole in 1987 [21]. One hour after oral administration of aqueous extract doses (190, 380 and $570 \mathrm{mg} / \mathrm{kg}$ ), methanol extract doses (100 and $200 \mathrm{mg} / \mathrm{kg}$ ), methanol extract fractions at 100 and $200 \mathrm{mg} / \mathrm{kg}$, indomethacin (Sigma, Spain) at $20 \mathrm{mg} / \mathrm{kg}$ (positive NSAID control) or 3\% tween 80 (negative control), and 30 mins after intraperitoneal administration of morphine (Braun Medical S.A., Spain), $20 \mu$ of 2.5\% formalin (formaldehyde 36.5\% solution, Sharlau, Spain) in saline solution was subcutaneously injected into the right hind paw of each mouse ( $n=6$ per group). Immediately, the animals were placed individually into a glass cylinder (20 cm in diameter) and a mirror was mounted at an angle of $45^{\circ}$ to allow clear observation of the animal's paws. The number of paw shakes (first phase) and the time in seconds the mice spent licking or biting (second phase) the formalin-injected paw was recorded, and taken as an indicator of pain response. Responses were measured between 0 and 5 min (first phase) and 15 - 30 min (second phase) after formalin injection, representing both the neurogenic and inflammatory pain responses, respectively.

\subsubsection{Tail-Flick Test}

The procedure used was similar to that used by Alviano et al. in 2004 [22] with slight modifications. The apparatus used consisted of a circulating immersion water heater. The thermostat was adjusted so that a constant temperature of $52^{\circ} \mathrm{C} \pm 2^{\circ} \mathrm{C}$ was maintained in the water bath. Before treatment, the terminal $3 \mathrm{~cm}$ of each mouse's tail was immersed in the water bath and the time in seconds taken to flick the tail was recorded. Only mice showing a pre-treatment reaction time less or equal to 4 seconds were selected for the study. Immediately after basal latency assessment, the three aqueous extract doses (190, 380 and $570 \mathrm{mg} / \mathrm{kg}$ p.o.), the two methanol extract doses (100 and $200 \mathrm{mg} / \mathrm{kg}$ p.o.), the four methanol extract fractions at $100 \mathrm{and} 200 \mathrm{mg} / \mathrm{kg}$ p.o. each, the positive control morphine (10 mg/kg i.p.) or 3\% 80 tween p.o. (negative control) were administered to groups of six mice and the reaction time was again measured 1 and $2 \mathrm{~h}$ after the treatment, except for morphine where measurement began 30 minutes after administration. Cut-off time was limited to 6 seconds for tail flick measurements to minimize tissue injury.

\subsection{Anti-Inflammatory Activity: Levy's Test}

Paw edema was induced according to the method described by Levy et al. in 1972 [23]. Mice were randomly divided into groups of six animals and pre-treated orally with four aqueous extract doses 190, 380, 570 and 760 
$\mathrm{mg} / \mathrm{kg}$, three methanol extract doses (100, 200 and $300 \mathrm{mg} / \mathrm{kg})$, two methanol extract fractions doses (100 and $200 \mathrm{mg} / \mathrm{kg}$ ), piroxicam at $75 \mathrm{mg} / \mathrm{kg}$ (positive control), and 3\% tween 80 (negative control). Thirty minutes later, edema was induced with the injection of $25 \mu \mathrm{l}$ of saline solution carrageenan (Sigma, Spain) into the right hind paw. The inflammation was quantified by measuring the thickness of each foot with a calibrator at 2 and $4 \mathrm{~h}$ after carrageenan injection. Results were expressed as variation in thickness between the right and left paws at $4 \mathrm{~h}$.

\subsection{Statistical Analyses}

Results are expressed as mean values \pm standard deviation of the mean (X $\pm \mathrm{SD})$. The statistical evaluation was carried out by analysis of variance (ANOVA) followed by Dunnett's test, and a probability level lower than 0.05 was considered as statistically significant (Student's $t$-test).

\section{Results}

\subsection{Antinociceptive Activity}

Antinociceptive activity was evaluated by phenylquinone writhing test, formalin test and tail-flick test. The effect of $S$. canariensis aqueous extract, methanol extract, methanol extract fractions and reference drug piroxicam in phenylquinone-induced writhing is shown in Figure 1. Piroxicam used at $75 \mathrm{mg} / \mathrm{kg}$ p.o. as the reference NSAID produced a significant strong analgesic effect (59.56\%; $\mathrm{p}<0.01)$ compared to the control group.

With respect to episodes of writhing, comparisons between the vehicle control group and experimental groups indicated that the oral administration of all extracts and fractions reduced phenylquinone-induced writhing in a dose-dependent manner. S. canariensis aqueous extract decreased the number of writhes by 5.33\%, 19.17\% and $42.53 \%$, respectively for the three doses assayed. The highest aqueous extract dose (570 mg/kg p.o. p < 0.05) showed an inhibiting effect comparable to that produced by the positive control piroxicam.

When methanol extract was tested, it was found that both the doses assayed of 100 and $200 \mathrm{mg} / \mathrm{kg}$ p.o. caused dose-dependent inhibition (32.35\% and 76.67\% respectively) on the writhing responses when compared with control, producing the dose of $200 \mathrm{mg} / \mathrm{kg}$ p.o. a higher significant protection $(\mathrm{p}<0.001)$ than the reference drug piroxicam.

With respect to the methanol extract fractions, only the ethyl acetate fraction at doses of $100 \mathrm{and} 200 \mathrm{mg} / \mathrm{kg}$ p.o. showed significant analgesic activity with $71.81 \%$ and $75.70 \%(p<0.001)$ inhibition respectively of phenylquinone-induced writhing episodes compared to controls, and this effect was also higher than that produced by the standard drug piroxicam.

The results of the antinociceptive effects of $S$. canariensis on formalin-induced paw pain response in mice are presented in Table 1. As shown, all the oral extracts and fractions doses reduced the number of paw shakes and the time that the animal spent licking the formalin-injected paw in both the neurogenic and inflammatory phases.

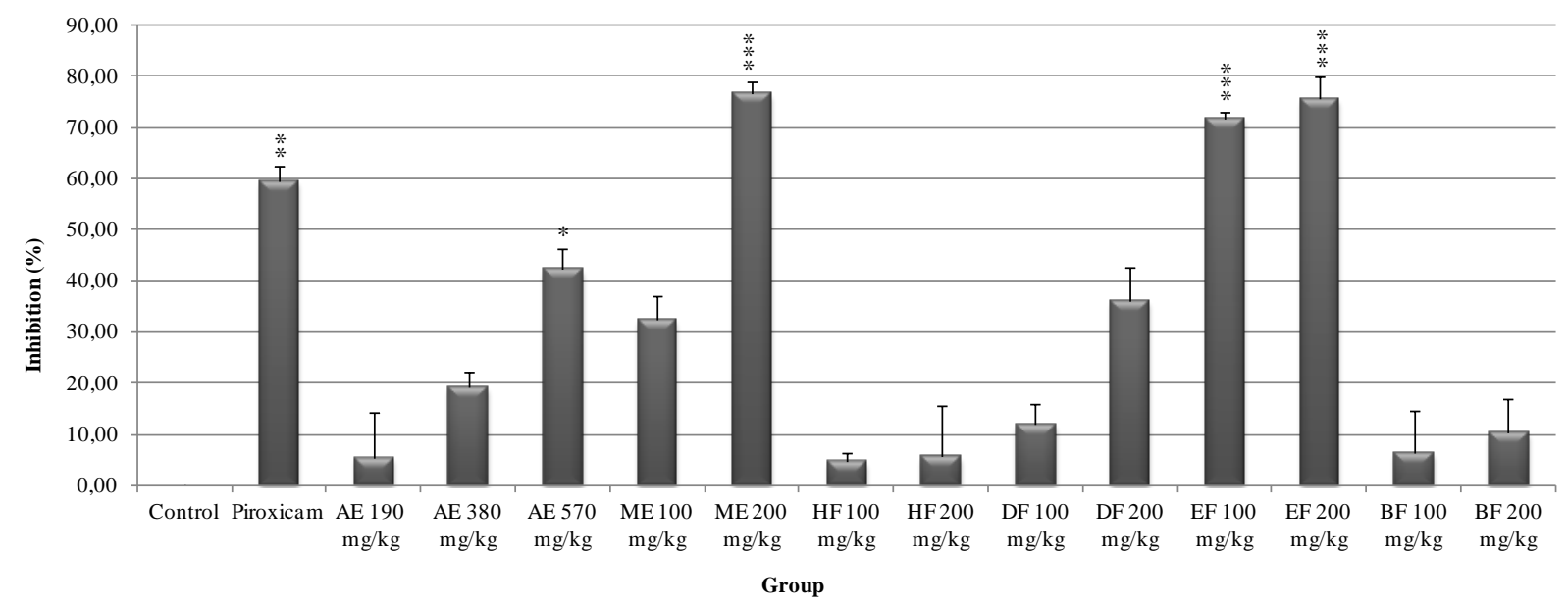

Figure 1. Effect of $S$. canariensis extracts and fractions on phenylquinone-induced writhing responses in mice. AE: aqueous extract; ME: methanol extract; HF: hexane fraction; DF: dichloromethane fraction; EF: ethyl acetate fraction; BF: n-butanol fraction. ${ }^{*} \mathrm{p}<0.05 ;{ }^{* *} \mathrm{p}<0.01 ;{ }^{* * * *} \mathrm{p}<0.001$ compared with the control group (Student's $t$-test). 
Table 1. Effect of S. canariensis extracts and fractions on the formalin-induced nociception in mice.

\begin{tabular}{|c|c|c|c|c|c|}
\hline \multirow{2}{*}{ Group } & \multirow{2}{*}{ Dose (mg/kg p.o.) } & \multirow{2}{*}{$\mathrm{X}_{1 \mathrm{st} \text { PHASE }}\left(\mathrm{n}^{\circ}\right) \pm$ S.D. } & \multirow{2}{*}{$\mathrm{X}_{2 \mathrm{nd} \text { PHASE }}(\mathrm{s}) \pm$ S.D. } & \multicolumn{2}{|c|}{ Inhibition (\%) } \\
\hline & & & & $1^{\text {st }}$ phase & $2^{\text {nd }}$ phase \\
\hline Control & - & $23.29 \pm 1.20$ & $325.75 \pm 35.29$ & - & - \\
\hline Morphine & $10^{\mathrm{a}}$ & $12.75 \pm 2.87^{* *}$ & $12.50 \pm 5.45^{* * *}$ & 45.26 & 96.16 \\
\hline Indomethacin & 20 & $18.64 \pm 2.87^{*}$ & $48.94 \pm 5.45^{* * *}$ & 19.96 & 84.98 \\
\hline \multirow{3}{*}{ Aqueous extract } & 190 & $20.76 \pm 3.08$ & $201.43 \pm 7.89^{*}$ & 10.86 & 38.16 \\
\hline & 380 & $19.35 \pm 4.87$ & $186.76 \pm 2.23^{* *}$ & 16.92 & 42.67 \\
\hline & 570 & $18.64 \pm 2.09$ & $85.50 \pm 2.93^{* * *}$ & 19.97 & 73.75 \\
\hline \multirow{2}{*}{ Methanol extract } & 100 & $19.75 \pm 8.63$ & $284.00 \pm 23.80$ & 15.20 & 12.82 \\
\hline & 200 & $18.62 \pm 2.22$ & $142.67 \pm 3.12^{* *}$ & 20.05 & 56.20 \\
\hline \multirow{2}{*}{ Hexane fraction } & 100 & $22.54 \pm 4.30$ & $293.07 \pm 13.67$ & 3.22 & 10.03 \\
\hline & 200 & $21.45 \pm 5.38$ & $291.63 \pm 9.54$ & 7.90 & 10.47 \\
\hline \multirow{2}{*}{ Dichloromethane fraction } & 100 & $20.48 \pm 7.39$ & $288.10 \pm 3.82$ & 12.07 & 11.56 \\
\hline & 200 & $20.40 \pm 2.05$ & $287.89 \pm 8.67$ & 12.41 & 11.62 \\
\hline \multirow{2}{*}{ Ethyl acetate fraction } & 100 & $19.75 \pm 8.63$ & $273.04 \pm 23.80$ & 15.20 & 16.18 \\
\hline & 200 & $18.54 \pm 2.73$ & $153.07 \pm 15.12^{* *}$ & 20.40 & 53.01 \\
\hline \multirow{2}{*}{ n-butanol fraction } & 100 & $20.64 \pm 5.20$ & $278.80 \pm 4.68$ & 11.38 & 14.41 \\
\hline & 200 & $19.84 \pm 4.32$ & $260.79 \pm 6.74$ & 14.81 & 19.94 \\
\hline
\end{tabular}

$\mathrm{X}_{1 \mathrm{st} \text { PHASE}}$ : mean of the number of shakes of the formalin-injected paw; $\mathrm{X}_{2 \text { nd PHASE}}$ : average time, in seconds, that the mouse spent licking the injected paw; S.D.: standard deviation of the mean; ${ }^{\mathrm{a}}$ intraperitoneally; ${ }^{*} \mathrm{p}<0.05 ;{ }^{* * *} \mathrm{p}<0.01 ;{ }^{* * *} \mathrm{p}<0.001$ compared with the control group (Student's $t$-test).

The opiate analgesic morphine caused a significant inhibitory effect on both phases of formalin-induced pain as compared to control, with values of $45.26(\mathrm{p}<0.01)$ and $96.16 \%(\mathrm{p}<0.001)$ respectively, and indomethacin produced a significant effect, especially in the second phases $(84.98 \%$; $<<0.001)$.

During the first phase, oral pre-treatment with all the extracts slightly reduced the animal responses. The aqueous extract at $570 \mathrm{mg} / \mathrm{kg}$, methanol extract at $200 \mathrm{mg} / \mathrm{kg}$ and ethyl acetate fraction at $200 \mathrm{mg} / \mathrm{kg}$ reduced the total number of paw shakes, by $19.97 \%, 20.05 \%$ and $20.40 \%$ respectively, in a similar manner than that produced by the NSAID indomethacin $(28.55 \%$; $p<0.05)$ when compared with the control group. Nevertheless, none of the extracts produced an inhibitory effect as great as morphine in this phase $(45.26 \%$; $<0.01)$, chosen as opiate analgesic drug.

The inhibitory effects of $S$. canariensis extracts were in general more pronounced in the second phase at the same doses. Pretreatment with the three aqueous extract doses significantly reduced pain in this phase in a dosedependent manner by 38.16\% ( $<<0.05)$, 42.67\% ( $<0.01$ ) and 73.75\% ( $<<0.001)$ respectively. On the other hand, the methanol extract and the ethyl acetate fraction, both at $200 \mathrm{mg} / \mathrm{kg}$, significantly reduced pain, with values of $56.20 \%$ and $53.01 \%$ ( $<<0.01$ ) respectively, when compared to vehicle control, remaining a little below the excellent values produced by the reference drugs used, indomethacin $(84.98 \%$; $p<0.001)$ or morphine (96.16\%; $\mathrm{p}<0.001)$ in this phase.

Concerning the antinociceptive effect of $S$. canariensis extracts and fractions on the tail-flick test in mice, while the reference opioid drug, morphine, produced a significant inhibition in the first and second hour after intraperitoneal injection (51.21\% ( $\mathrm{p}<0.01$ ) and 81.82\% ( $\mathrm{p}<0.001$ ) respectively), none of the extracts doses assayed produced an important increase in the reaction time to thermal stimuli; the most active dose resulted in a reduction of only $18.35 \%$, well below the $81.82 \%$ of morphine (data not shown).

\subsection{Anti-Inflammatory Activity: Levy's Test}

The reduction in foot thickness after carrageenan-induced paw edema injection in animals treated with $S$. canariensis extracts and piroxicam in relation to the negative control group is presented in Figure 2. The doses assayed of $S$. canariensis extracts and fractions were moderately active in a dose-dependent manner, with the aqueous extract at 570 and $760 \mathrm{mg} / \mathrm{kg}$ (16.67\% and 23.50\% respectively) achieving the greatest inhibition, fol- 


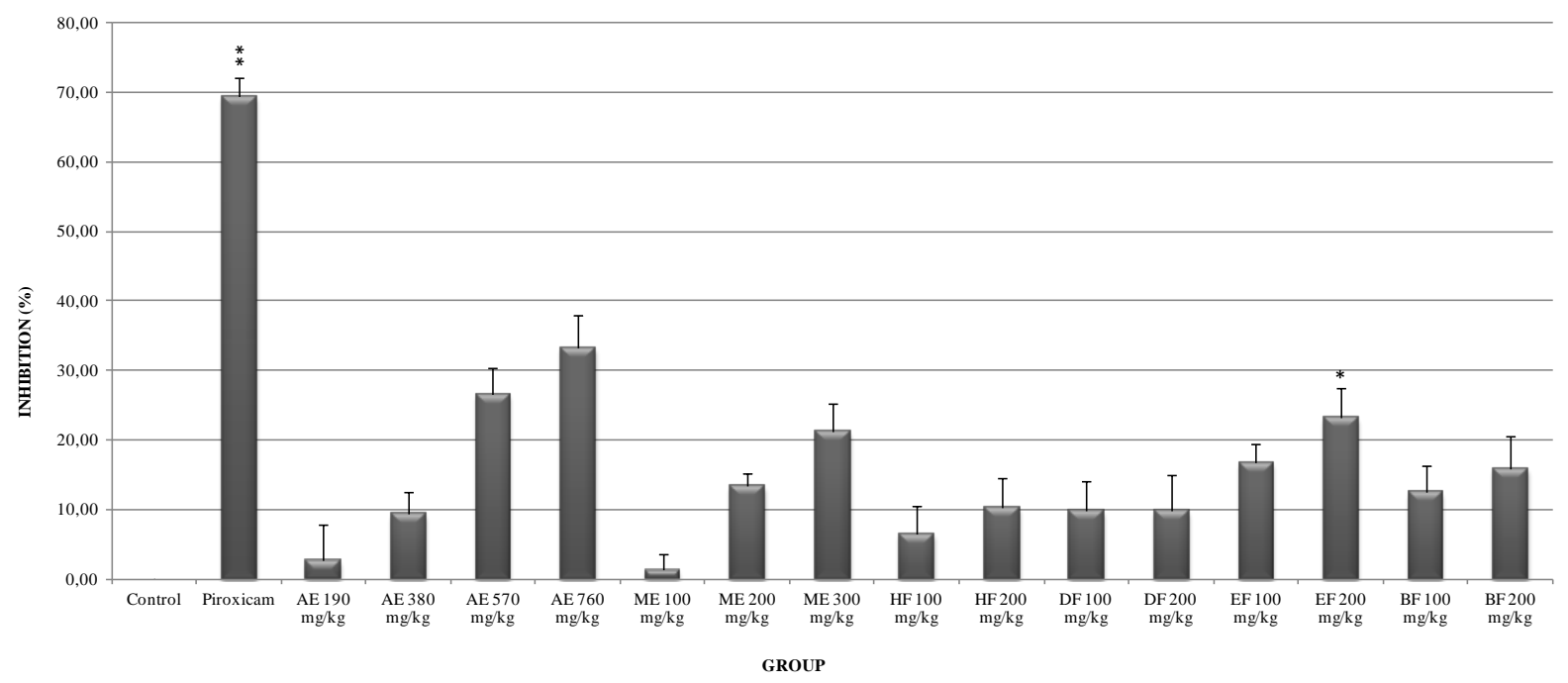

Figure 2. Effect of $S$. canariensis extracts and fractions on the carrageenan-induced hind paw edema in mice. AE: aqueous extract; ME: methanol extract; HF: hexane fraction; DF: dichloromethane fraction; EF: ethyl acetate fraction; BF: n-butanol fraction. ${ }^{*} \mathrm{p}<0.05 ;{ }^{* *} \mathrm{p}<0.01$ compared with the control group (Student’s $t$-test).

lowed by the methanol extract at $300 \mathrm{mg} / \mathrm{kg}(21.10 \%)$ and once again the ethyl acetate fraction at $200 \mathrm{mg} / \mathrm{kg}$ (33.33\%; $\mathrm{p}<0.05$ ), at $4 \mathrm{~h}$ after carrageenan injection. Nevertheless, none of the extracts assayed showed the significant and high protection offered by piroxicam at $75 \mathrm{mg} / \mathrm{kg}(69.33 \%$; $\mathrm{p}<0.01)$.

\section{Discussion and Conclusions}

The in vivo effects of $S$. canariensis extracts, after acute treatments using analgesic and anti-inflammatory assays, were studied to substantiate the use of this species in traditional Canary folk medicine.

Different irritant chemical agents can be used as nociceptive stimuli to assess pain and pre-clinically evaluate analgesic drugs, such as phenylquinone and formalin [24]. The phenylquinone-induced writhing test is used to assess peripheral anti-nociceptive effects of test compounds and is considered to be a visceral pain model [25]. This test is based on phenylquinone stimulation of nociceptive neurons by liberation of mediators such as histamine, serotonin, cytokines, and eicosanoids, especially prostaglandin $\mathrm{E}_{2}\left(\mathrm{PGE}_{2}\right)$ in the peritoneal fluid [26]. Activation and sensitization of peripheral chemosensitive nociceptive receptors by this mediator lead to constrictions of the abdominal wall and twisting of the trunk followed by extension of hind limbs, associated with development of peripheral inflammation [27]. Since S. canariensis extracts have shown significant activity against pain induced by phenylquinone, compared to the control group, these data indicate that $S$. canariensis extracts have an analgesic effect on inflammatory pain. This activity of $S$. canariensis extracts may be related to reduced liberation of inflammatory mediators or a direct blockage of receptors.

In order to obtain more specific evidence of the nociceptive activity of S. canariensis, formalin test was used. The formalin-induced nociception test, a reliable test to exploit analgesic activity, is used to measure the ability of a substance to attenuate moderate continuous pain generated by injured tissue. Behavioral indicators (paw shakes and licking) were used to assess the analgesic effect in this study. The early and late phases of formalin nociception are considered to represent neurogenic and inflammatory pain behavior, respectively [28]. The first phase (neurogenic pain) is acute and represents the direct chemical stimulation of nociceptors caused by a direct effect of formalin on sensory C-fibers, and is thought to involve substance P, glutamate and bradykinin. The second phase (inflammatory pain) is tonic and appears to be dependent on the combination of a central sensitization and an inflammatory reaction in the peripheral tissue, which releases nociceptive mediators including histamine, serotonin, PG and bradykinin [21]. Centrally acting drugs such as morphine inhibit both phases of pain, while peripheral acting drugs, such as acetylsalicylic acid, inhibit mainly the second phase [29]. In this study, the oral administration of $S$. canariensis extracts significantly reduced the number of paw shakes and licking in a dose-dependent manner, especially in the second phase of the formalin test, thus indicating a predominantly peripheral action. 
In order to rule out a possible central involvement in the antinociceptive effect of $S$. canariensis extracts and fractions, the tail flick test was conducted. This test uses a short thermal stimulus and the behavioral responses measured are considered to be supraspinally integrated responses, so it is suitable for evaluation of centrally but not of peripherally acting analgesic drugs. Compounds exhibiting good antinociceptive effect in this method may be considered as potent central analgesics [16]. Although S. canariensis displayed a significant antinociceptive response on Siegmund and formalin test, it produced a very slight effect on tail-flick test, which indicates little central neurotransmission [30].

The results obtained suggest that $S$. canariensis extracts may act predominantly via inflammatory pain, so we studied their effects in a standard experimental model of acute inflammation, the carrageenan-induced paw edema. Carrageenan has been widely used as a noxious agent to induce experimental inflammation for the screening of compounds possessing anti-inflammatory activity [31]. This phlogistic agent, when injected locally into the rat paw, produces a severe inflammatory reaction, which is discernible within 30 mins [32]. In addition, this model is known to be the acute inflammatory model sensitive to COX inhibitors and has been used to evaluate the effect of NSAIDs, which primarily inhibit the COX involved in PG synthesis [33].

Subcutaneous injection of carrageenan into the mouse paw produces inflammation resulting from a biphasic release of various inflammatory mediators. Histamine, serotonin and bradykinin are the first detectable mediators in the early phase of carrageenan-induced inflammation; PGs are involved in the increased vascular permeability and are detectable in the late phase of inflammation. Local and/or systemic inflammation is associated with enhanced levels of the pro-inflammatory cytokines TNF- $\alpha$, IL-1, and IL-6 [34]. The initial phase of edema, which is not inhibited by NSAIDs such as indomethacin or aspirin, begins immediately after injection of carrageenan and diminishes in $2 \mathrm{~h}$. It has been attributed to the release of histamine, 5-hydroxytryptamine (5-HT) and bradykinin. The second accelerating phase of swelling begins at the end of the first phase and remains through 3 to $5 \mathrm{~h}$. It has been correlated with the elevated production of PGs, protease and lysosome, and more recently has been attributed to the induction of inducible COX-2 in the hind paw. This phase can be blocked by NSAIDs [35]. Local neutrophil infiltration and activation also contribute to this inflammatory response by producing, among other mediators, oxygen-derived free radicals such as superoxide anion $\left(\mathrm{O}_{2}^{-}\right)$and hydroxyl radicals. Despite their involvement in natural processes, these reactive species (if released in excess) are able to oxidize cell membranes, alter protein structure and initiate degenerative processes [36].

The in vivo anti-inflammatory activities of $S$. canariensis extracts and fractions against carrageenan-induced paw edema were confirmed with reduced paw volume in the second phase of swelling in the same manner as NSAIDs, however, the inhibition of mouse paw edema observed with $S$. canariensis extracts was relatively lower than that of the positive control, piroxicam.

In this assay and taking into account that anti-inflammatory activity may need higher doses of drugs, we introduced one more dose of each extract based on the fact that higher doses of S. canariensis may contain higher concentrations of active compounds and could therefore produce greater inhibition of carrageenan-induced edema, although only the two lowest doses of the aqueous extract here studied are used in traditional medicine.

Previous investigations by our group have shown an interesting dose-dependent diuretic activity in laboratory assays for the aqueous and several organic extracts of $S$. canariensis, which appeared to be related to its potassium content and to the presence of polar organic compounds (flavonoids and steroidal saponins) and organic fatty acids [12] [13] in the most active ethylacetate fraction.

The excellent results obtained in this study with the aqueous and methanol extract on analgesic and anti-inflammatory activities motivated further study into the demonstrated properties. That is why we proceeded to fractionate the methanol extract of the plant using various polar solvents. The new fractions were submitted to the same assays for anti-nociceptive and anti-inflammatory activities at 100 and $200 \mathrm{mg} / \mathrm{kg}$ bw, showing that the most effective dose was $200 \mathrm{mg} / \mathrm{kg}$. Rather than attempt to determine dose/effect results with the sub-extracts, in this phase of the study we wished only to determine which of the fractions was most active, assuming that the most active fraction would contain the chemical compounds responsible for the activities under study.

Present data obtained using the purified S. canariensis fractions further demonstrate the interesting analgesic effects, more than the anti-inflammatory effects, confirmed for the aqueous and methanol extract of this species. Although all the fractions tested demonstrated a degree of analgesic activity, we observed a maximum expression and statistical significance with the polar ethyl acetate fraction that yielded excellent values of $75.70 \%$ and $53.01 \%$ analgesic activity in phenylquinone or formalin-induced pain respectively when compared with the control group. This significant activity was greater than that obtained using piroxicam (59.56\%) but lower than 
those of morphine (96.16\%) or indomethacin (84.98\%), used as reference analgesic drugs.

The fact that the intermediate polar ethyl acetate fraction tested also produced the highest degree of analgesic activity leads us to conclude that the analgesic activity of the plant was possibly due to the presence of phenolic polar compounds and fatty acids previously identified in this fraction, favoring the hypothesis that both types of constituents appear to be involved in the pharmacological action observed. So these substances might be responsible, at least in part, for the observed activity and they may act individually or synergistically.

Numerous phenolic compounds, especially flavonoids, inhibit the inflammatory response and comprise the main class of compounds present in the Smilax genus. These active principles have been studied extensively for their various biological effects, and have demonstrated interesting analgesic and anti-inflammatory properties [14]-[18].

It is possible that the analgesic and anti-inflammatory effect of the $S$. canariensis extracts is based on the presence of these active principles, which act by blocking COX and decreasing PG production, and 5-lipooxygenase pathways [17] [37]. Antinociceptive activity has been shown in acetic acid and p-benzoquinone-induced writhing tests [38]. Also, Fawzy et al. in 1988 [39] showed that flavonoids are inhibitors of phospholipase $\mathrm{A}_{2}$ enzyme, which catalyzes the hydrolysis of membrane phospholipids to release arachidonic acid, a precursor of PG synthesis. In addition to phenolic compounds, S. canariensis contains other important secondary metabolites belonging to the class of fatty acids, which may also participate in modulating the anti-inflammatory response [40].

Thus the phenolic compounds present in this plant may be responsible for anti-inflammatory and analgesic activities observed in S. canariensis. However, the involvement of other secondary metabolites, such as fatty acids, present in the plant cannot be ruled out.

Regarding adverse effects, neither the infusions nor the methanol extract used in the tests produced acute toxicity in the mice tested, as evidenced by the absence of mortality in the animals during the study period. Moreover, no macroscopic alterations were noted in the viscera of the treated mice after oral administration by means of a gastric catheter $1 \mathrm{ml} / 40 \mathrm{~g}$ bw of increasing doses of the aqueous extract up to $5.0 \mathrm{~g} / \mathrm{kg}$ bw fresh dry material and methanol extract up to $1 \mathrm{~g} / \mathrm{kg}$ bw, respectively [12]. So the absence of acute toxicity lends support to the safety profile of $S$. canariensis since doses much higher than those typically used dosage in folk-medicine failed to elicit any toxic symptoms in the test rodents.

In summary, the present work shows for the first time that oral ingestion by mice of $S$. canariensis extracts safely produce marked antinociceptive effects in different experimental models of nociception. The results of phenylquinone-induced writhing test, formalin test, and tail flick test indicate that $S$. canariensis extracts act more peripherally than centrally to achieve pain relief. These extracts also showed a moderate anti-inflammatory activity.

Taking together all the data here obtained, we can affirm that these results clearly demonstrate the analgesic activity of $S$. canariensis in experimental animals, which supports the ethno-medicinal data available regarding this species. The fact that the simple infusions provided antinociceptive effects comparable to the more difficult to obtain methanol extract suggests that traditional folk-medicine infusions (aqueous extract) need not be replaced by more costly chemically processed products.

\section{Conclusion}

Our data seem to indicate that the analgesic effect of $S$. canariensis is associated with the phenolic compounds contained in the fraction of intermediate polarity (ethyl acetate), and decreased in the most extreme apolar and polar extracts (dichloromethane, n-butanol and methanol respectively). Further research is underway at our laboratory to determine the mechanism of these pharmacological actions, and particularly to identify the principal components using spectroscopic methods.

\section{Acknowledgements}

This work was supported by a local government grant (from Consejería de Educación, Cultura y Deportes del Gobierno de Canarias).

\section{Declaration of Interest}

The authors declare they have no conflict of interest. 


\section{References}

[1] Cope, D.K. and Lariviere, W.R. (2006) Gene Therapy and Chronic Pain. Scientific World Journal, 31, $1066-1074$. http://dx.doi.org/10.1100/tsw.2006.197

[2] Woodcock, J., Witter, J. and Dionne, R.A. (2007) Stimulating the Development of Mechanism-Based, Individualized Pain Therapies. Nature Reviews Drug Discovery, 6, 703-710. http://dx.doi.org/10.1038/nrd2335

[3] Eming, S.A., Krieg, T. and Davidson, J.M. (2007) Inflammation in Wound Repair: Molecular and Cellular Mechanisms. Journal of Investigative Dermatology, 127, 514-525. http://dx.doi.org/10.1038/sj.jid.5700701

[4] Reanmongkol, W., Itharat, A. and Bouking, P. (2007) Evaluation of the Anti-Inflammatory, Antinociceptive and Antipyretic Activities of the Extracts from Smilax corbularia Kunth Rhizomes in Mice and Rats (in Vivo). Songklanakarin Journal of Science and Technology, 29, 59-67.

[5] Chanda, S. and Dave, R. (2009) In Vitro Models for Antioxidant Activity Evaluation and Some Medicinal Plants Possessing Antioxidant Properties: An Overview. African Journal of Microbiology Research, 3, 981-996.

[6] Kubo, S., Mimaki, Y., Sashida, Y., Mimaki, Y. and Sashida, Y. (1992) Steroidal Saponins from the Rhizomes of Smilax sieboldii. Phytochemistry, 31, 2445-2450. http://dx.doi.org/10.1016/0031-9422(92)83296-B

[7] Chen, T., Li, J.X. and Xu, Q. (2000) Phenylpropanoid Glycosides from Smilax glabra. Phytochemistry, 53, $1051-1055$. http://dx.doi.org/10.1016/S0031-9422(99)00522-1

[8] Li, S.Y., Fuchino, H., Kawahara, N., Sekita, S. and Satake, M. (2002) New Phenolic Constituents from Smilax bracteata. Journal of Natural Products, 65, 262-266. http://dx.doi.org/10.1021/np010338m

[9] Shao, B., Guo, H., Cui, Y., Ye, M., Han, J., et al. (2007) Steroidal Saponins from Smilax china and Their Anti-Inflammatory Activities. Phytochemistry, 68, 623-630. http://dx.doi.org/10.1016/j.phytochem.2006.10.026

[10] Pérez de Paz, P.L. and Hernández Padrón, C.E. (1999) Plantas medicinales o útiles en la Flora Canaria. Aplicaciones Populares, Francisco Lemus S.L., La Laguna, 161.

[11] Schaefer, H. and Schoenfelder, P. (2009) Smilax canariensis, S. azorica (Smilacaceae) and the Genus Smilax in Europe. In: Beltrán Tejera, E., Afonso-Carrillo, J., García Gallo, A. and Rodríguez Delgado, O., Eds., Homenaje al Profesor Dr. Wolfredo Wildpret de la Torre, Instituto de Estudios Canarios, La Laguna (Tenerife. Islas Canarias), Monografía LXXVIII, 297-306.

[12] Abdala, S., Martín-Herrera, D., Benjumea, D., et al. (2008) Diuretic Activity of Smilax canariensis, an Endemic Canary Island Species. Journal of Ethnopharmacology, 119, 12-16. http://dx.doi.org/10.1016/j.jep.2008.05.025

[13] Abdala, S., Martín-Herrera, D., Benjumea, D., et al. (2012) Diuretic Activity of Some Smilax canariensis Fractions. Journal of Ethnopharmacology, 140, 277-281. http://dx.doi.org/10.1016/j.jep.2012.01.017

[14] Harbone, J.B. and Williams, C.A. (2000) Advances in Flavonoid Research Since 1992. Phytochemistry, 55, $481-504$. http://dx.doi.org/10.1016/S0031-9422(00)00235-1

[15] Küpeli, E. and Yesilada, E. (2007) Flavonoids with Anti-Inflammatory and Antinociceptive Activity from Cistus laurifolius L. Leaves through Bioassay-Guided Procedures. Journal of Ethnopharmacology, 112, 524-530. http://dx.doi.org/10.1016/j.jep.2007.04.011

[16] Vidyalakshmi, K., Kamalakannan, P., Viswanathan, S., et al. (2010) Antinociceptive Effect of Certain Dihydroxy Flavones in Mice. Pharmacology Biochemistry and Behavior, 96, 1-6. http://dx.doi.org/10.1016/j.pbb.2010.03.010

[17] Li, Y.D., Frenz, C.M., Chen, M.H., et al. (2011) Primary Virtual and in Vitro Bioassay Screening of Natural Inhibitors from Flavonoids against COX-2. Chinese Journal of Natural Medicines, 9, 156-160.

[18] Higgs, J., Wasowski, C., Loscalzo, L.M., et al. (2013) In Vitro Binding Affinities of a Series of Flavonoids for $\mu$-Opioid Receptors. Antinociceptive Effect of the Synthetic Flavonoid 3, 3-Dibromoflavanone in Mice. Neuropharmacology, 72, 9-19. http://dx.doi.org/10.1016/j.neuropharm.2013.04.020

[19] Directive 2010/63/EU of the European Parliament and of the Council of 22 September 2010 on the Protection of Animals Used for Scientific Purposes.

[20] Siegmund, E., Cadmus, R. and Lu, G. (1957) A Method for Evaluating Both Non-Narcotic and Narcotic Analgesics. Experimental Biology and Medicine, 95, 729-731. http://dx.doi.org/10.3181/00379727-95-23345

[21] Hunskaar, S. and Hole, K. (1987) The Formalin Test in Mice. Dissociation between Inflammatory Pain. Pain, 30, 103114. http://dx.doi.org/10.1016/0304-3959(87)90088-1

[22] Alviano, D.S., Rodrigues, K.F., Leitao, S.G., et al. (2004) Antinociceptive and Free Radical Scavenging Activities of Cocos nucifera L. (Palmae) Husk Fiber Aqueous Extract. Journal of Ethnopharmacology, 92, 269-273. http://dx.doi.org/10.1016/j.jep.2004.03.013

[23] Levy, G., Tuschima, T. and Amsel, L.P. (1972) Limited Capacity for Salicyl Phenolic Glucuronide Formation and Its Effect on the Kinetics of Salicylate Elimination in Man. Clinical Pharmacology \& Therapeutics, 13, 258. 
[24] Barrot, M. (2012) Tests and Models of Nociception and Pain in Rodents. Neuroscience, 211, 39-50. http://dx.doi.org/10.1016/j.neuroscience.2011.12.041

[25] Le Bars, D., Gozariu, M. and Cadden, S.W. (2001) Animal Models of Antinociception. Pharmacological Reviews, 53, 597-652.

[26] Lucarini, R., Bernardes, W.A., Ferreira, D.S., et al. (2013) In Vivo Analgesic and Anti-Inflammatory Activities of Rosmarinus officinalis Aqueous Extract, Rosmarinic Acid and Its Acetyl Ester Derivative. Pharmaceutical Biology, 51, 1087-1090. http://dx.doi.org/10.3109/13880209.2013.776613

[27] Kawabata, A. (2011) Prostaglandin $\mathrm{E}_{2}$ and Pain-An Update. Biological and Pharmaceutical Bulletin, 34, $1170-1173$. http://dx.doi.org/10.1248/bpb.34.1170

[28] Soldi, C., Pizzolatti, M.G., Luiz, A.P., et al. (2008) Synthetic Derivatives of the $\alpha$ - and $\beta$-Amyrin Triterpenes and Their Properties. Bioorganic \& Medicinal Chemistry, 16, 3377-3386. http://dx.doi.org/10.1016/j.bmc.2007.12.008

[29] Udobang, J.A., Nwafor, P.A. and Okokon, J.E. (2010) Analgesic and Antimalarial Activities of Crude Leaf Extract and Fractions of Acalypha wilkensiana. Journal of Ethnopharmacology, 127, 373-378. http://dx.doi.org/10.1016/j.jep.2009.10.028

[30] Pinheiro, M.M.G., Radulović, N.S., Miltojević, A.B., et al. (2014) Antinociceptive Esters of N-Methylanthranilic Acid: Mechanism of Action in Heat-Mediated Pain. European Journal of Pharmacology, 727, 106-114. http://dx.doi.org/10.1016/j.ejphar.2013.12.042

[31] Prajapati, V.D., Maheriya, P.M., Jani, G.K., et al. (2014) Carrageenan: A Natural Seaweed Polysaccharide and Its Applications. Carbohydrate Polymers, 105, 97-112. http://dx.doi.org/10.1016/j.carbpol.2014.01.067

[32] Bhandare, A.M., Kshirsagar, A.D., Vyawahare, N.S., et al. (2010) Potential Analgesic, Anti-Inflammatory and Antioxidant Activities of Hydroalcoholic Extract of Areca catechu L. Nut. Food and Chemical Toxicology, 48, 3412-3417. http://dx.doi.org/10.1016/j.fct.2010.09.013

[33] Rodrigues, I.V., Souza, J.N.P., Silva, A.C.G., et al. (2013) Antiedematogenic and Antinociceptive Effects of Leaves Extracts from Protium spruceanum Benth. (Engler). Pharmacognosy Journal, 5, 6-12. http://dx.doi.org/10.1016/j.phcgj.2012.08.001

[34] Cuzzocrea, S., Sautebin, L., De Sarro, G., et al. (1999) Role of IL-6 in the Pleurisy and Lung Injury Caused by Carrageenan. Journal of Immunology, 163, 5094-5104.

[35] Eddouks, M., Chattopadhyay, D. and Zeggwagh, N.A. (2012) Animal Models as Tools to Investigate Antidiabetic and Anti-Inflammatory Plants. Evidence-Based Complementary and Alternative Medicine, 2012, 1-14.

[36] Posadas, I., Bucci, M., Roviezzo, F., et al. (2004) Carrageenan-Induced Mouse Paw Oedema Is Biphasic, Age-Weight Dependent and Displays Differential Nitric Oxide Cyclooxygenase-2 Expression. British Journal of Pharmacology, 142, 331-338. http://dx.doi.org/10.1038/sj.bjp.0705650

[37] Toffoli-Kadri, M.C., Carollo, C.A., Dias Lourenço, L., et al. (2014) In Vivo and in Vitro Anti-Inflammatory Properties of Achyrocline alata (Kunth) DC. Journal of Ethnopharmacology, 153, 461-468. http://dx.doi.org/10.1016/j.jep.2014.03.008

[38] Toker, G., Kupeli, E., Memisoglu, M., et al. (2004) Flavonoids with Antinociceptive and Anti-Inflammatory Activities from the Leaves of Tilia argentea (Silver Linden). Journal of Ethnopharmacology, 95, 393-397. http://dx.doi.org/10.1016/j.jep.2004.08.008

[39] Fawzy, A.A., Vishwanath, B.S. and Franson, R.C. (1988) Inhibition of Human Non-Pancreatic Phospholipases A2 by Retinoids and Flavonoids. Agents and Actions, 25, 394-400. http://dx.doi.org/10.1007/BF01965048

[40] Mori, T.A. and Beilin, L.J. (2004) Omega-3 Fatty Acids and Inflammation. Current Atherosclerosis Reports, 6, 461467. http://dx.doi.org/10.1007/s11883-004-0087-5 